\title{
New porcine model of perineal tear and its utility in physicians' training on the reconstruction of 3rd and 4th degree perineal tear during vaginal delivery
}

\author{
Przemysław Ciesielski ${ }^{1,2}$, Małgorzata Kołodziejczak ${ }^{1}$, Paweł Dutkiewicz² \\ ${ }^{1}$ Warsaw Proctology Centre, Saint Elisabeth Hospital, Warsaw, Poland \\ ${ }^{2}$ Department of General Surgery, District Hospital in Wołomin, Poland
}

\begin{abstract}
Objectives: One of the most serious complications of vaginal delivery is $3 \mathrm{rd}$ and 4 th degree perineal tear and its incorrect management results in anal incontinence. Animal-based anatomical models of childbirth-induced perineal tear are an important element of the physicians' practical training [1]. The proposed new model, prepared using porcine tongue and intestine, closely mimics all the tissues and organs subjected to injury during complicated deliveries and constitutes an educational opportunity for the reconstruction of the injuries.

The objective of this paper was to present a new porcine model of the perineum and to evaluate the utility of this model in the training of physicians on the reconstruction of the 3rd and 4th degree perineal tear during childbirth.

Material and method: We presented a preparation method of the proposed model and a calculation of the amount of time and costs required for its preparation. The utility of the model was assessed using a questionnaire completed by the participants of a workshop conducted with the model.

Results: We found that $95 \%$ of the respondents had never practiced perineal reconstruction on any model. According to $85 \%$ of the respondents, our model was very similar to natural tissues. According to $95 \%$ of the respondents, the simulated model of the perineal tear satisfactorily mimicked the real-life situation.

Conclusion:The presented model is cheap and easy to prepare. It satisfactorily mimics the tissues and tissue injuries caused by the tear, making it helpful in training physicians on the reconstruction of 3rd and 4th degree perineal tear.
\end{abstract}

Keywords: perineal tear, sphincter reconstruction, animal model of perineal tear

Ginekologia Polska 2018; 89, 10: 558-562

\section{INTRODUCTION}

Perineal injuries of various degrees occur in approximately $80 \%$ of natural deliveries [2], of which 3rd and 4 th degree perineal tears constitute approximately 4 to $11 \%$ [3, 4]. Sphincter insufficiency of various degrees occurs in 15 to $61 \%$ of women who suffered perineal tear during childbirth $[4,5]$. Proper primary repair of the perineal tear is of the utmost importance for the limitation of incontinence caused by childbirth-induced injury [4]. Good personnel training is a fundamental precondition for achieving this goal $[6,7]$.

The problem with perineal tear repair, in particular 4th degree tear, is due to its multidisciplinary nature. Perineal reconstruction of 1-3a degree tears is usually performed by gynecologists. However, 3b-4 degree tears often require consultation or assistance from a colorectal surgeon, whose experience in sphincter reconstruction is greater, but may be not sufficient for the reconstruction of other perineal tissues. Therefore, both gynecologists and surgeons should undergo training, especially since tear repair is usually required during on-call duty, when the possibility of consultation with an experienced gynecologist or surgeon may be limited.

Based on bovine-based animal models described in the literature [1], we developed a new porcine model, which unlike the existing models, mimics not only the rectum 
and anal sphincters, but also the vagina and bulbospongiosus muscles. Our model may be used for training of both gynecologists and surgeons on the reconstruction of sphincters and other perineal tissues.

\section{Objectives}

The aim of this paper was to present a new porcine model that mimics the perineal tear and to evaluate the utility of this model in the training of physicians on the reconstruction of the $3 \mathrm{rd}$ and 4 th degree perineal tear during childbirth.

\section{MATERIALS AND METHODS}

\section{Model preparation}

The following tissues and instruments were used to prepare the model:

- tissues: one porcine tongue, approximately $10 \mathrm{~cm}$ of porcine small intestine (Fig. 1),

- instruments: one scissors, one curved forceps, one knife, one surgical holder, one surgical suture.

The preparation of a single specimen took approximately 20 minutes. An estimated cost of the whole model (tissues and sutures) was approximately PLN 40 (USD 12). The tongue was placed with its ventral surface facing upward and the longitudinal muscles that were stretching from the tongue base to its half-length were removed, so that the cranial part of the tongue had uniform thickness (Fig. 2). Subsequently, cruciate incisions were made at the

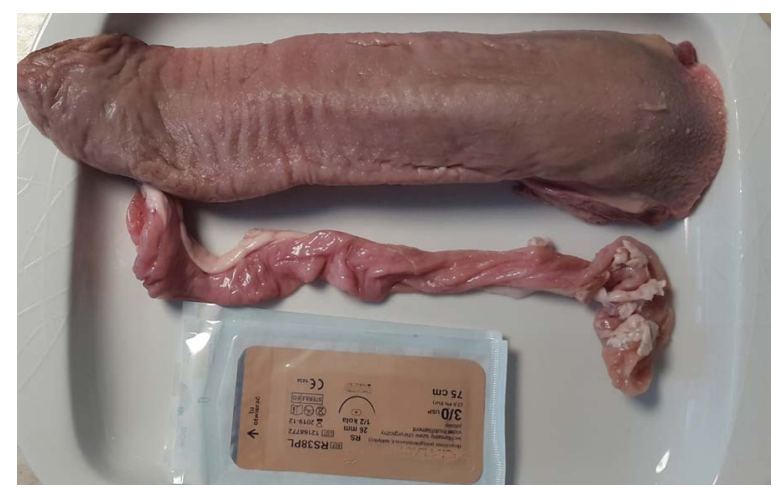

Figure 1. Materials required for preparation of the specimen

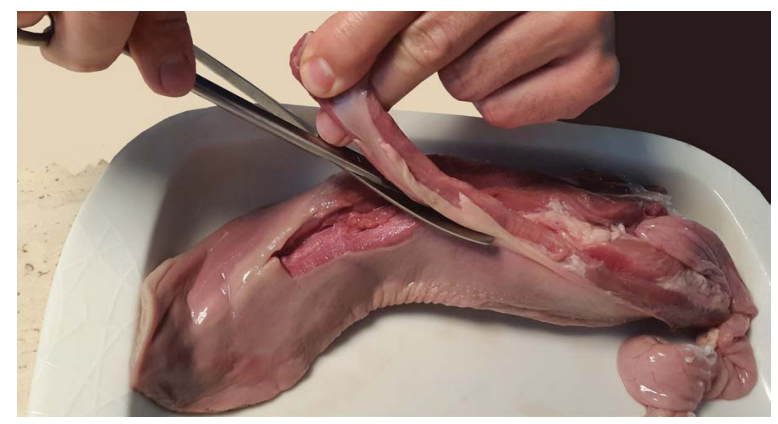

Figure 2. Cutting of muscles at the base of the tongue base on its dorsal surface, throughout the entire thickness of the tongue, at the level of clearly visible taste buds. Both incisions, the vertical and horizontal one, did not exceed 10-12 $\mathrm{mm}$. An index finger was passed freely through the incisions. Then, previously prepared porcine small intestine was passed through this hole and sutured using a continuous suture, forming a canal that mimicked the anus (Fig. 3, 4). Subsequently, a spindle-like incision was made along the tongue on its dorsal surface, mimicking the vulva (Fig. 5). The spindle-like fragment of the resected tissue was approximately $100 \mathrm{~mm}$ long, $10-12 \mathrm{~mm}$ in width and $10 \mathrm{~mm}$

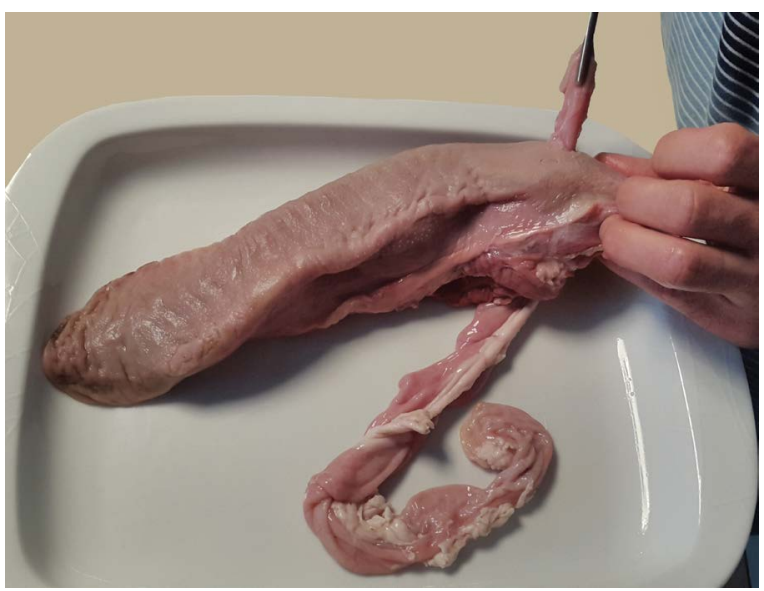

Figure 3. Passing the intestine through the incision at the base of the tongue

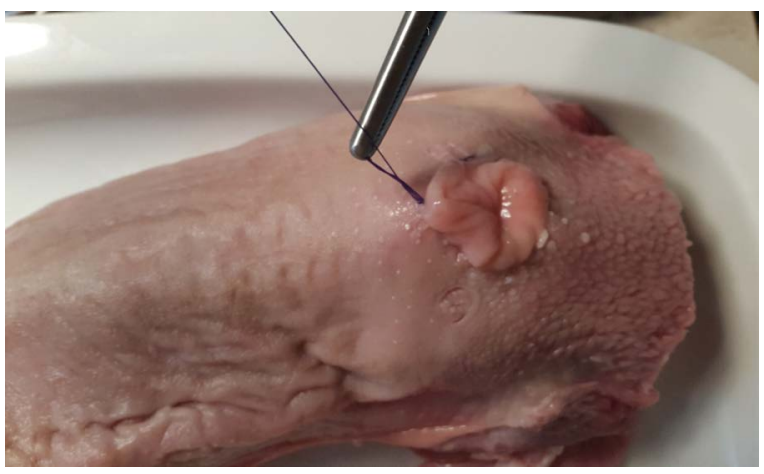

Figure 4. Suturing of the intestine at the dorsal surface of the tongue imitating the anus

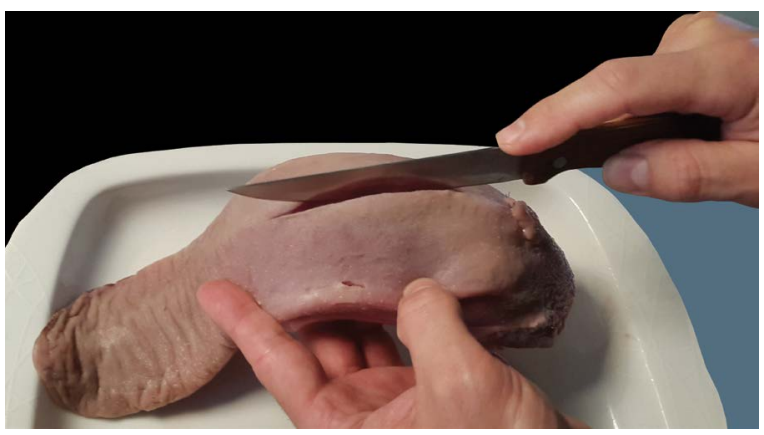

Figure 5. Spindle-like incision imitating the vulva 
in depth. In the inferior part of the incision, an approximately $20 \mathrm{~mm}$ longitudinal penetrating cut in the tongue was made - two fingers were freely passed through this hole (Fig. 6). Next, from the bottom and through this hole the second part of the intestine was passed and sutured, forming the "vagina" (Fig. 7, 8). Subsequently, approximately 7-10 mm incisions were made on both sides of the tongue, on its lateral surfaces, at the level of the superior margin of the previously formed anus. Through the incision, under the guidance of the finger in the "anus", the curved forceps was passed, forming an arcuate tunnel between the incisions. Through the tunnel of approximately $8-10 \mathrm{~mm}$ diameter, a muscular band was passed, previously prepared from excised longitudinal bundles of muscle from the ventral part of the tongue, mimicking the anal sphincters (Fig. 9). Both ends of the bundle protruding

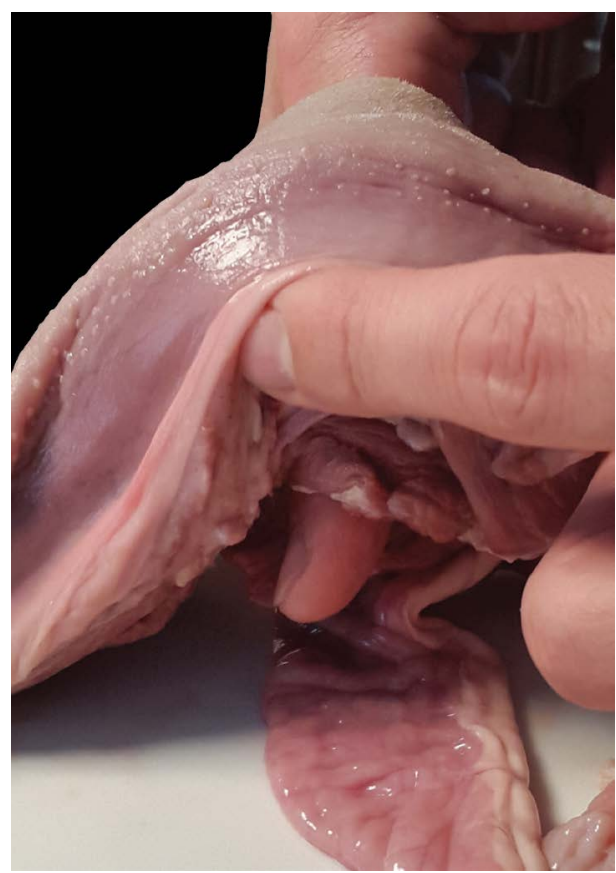

Figure 6. Creation of a hole mimicking the vagina

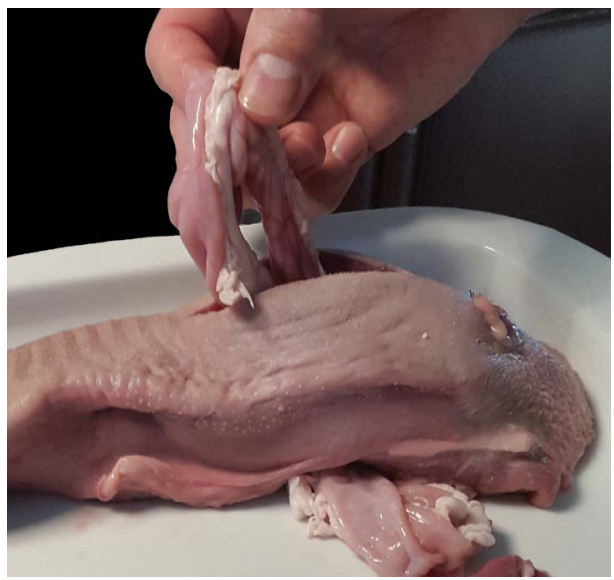

Figure 7. Passing of an intestine at the site of the created vagina outside the tunneled part were sutured with single sutures to make them fixed (Fig. 10). The muscle layer of the tongue remained in front of the created sphincter, mimicking the bulbospongiosus muscles. The final appearance of the prepared model is presented on image 11 (Fig. 11). Next, the model was cut from the posterior wall of the "vagina" to the anterior wall of the "anus" through all the layers, approximately 10-15 mm deep, mimicking a 4th degree tear. Such models were presented to the workshop participants.

The model was evaluated by medical specialists and physicians training in the field of Gynecology during two practical workshop sessions dedicated to the repair of childbirth injuries. Forty models were prepared. Each trainee first performed a reconstruction of the perineal tear mimicked in our model, and then completed the questionnaire (Fig. 12). A total of 40 physicians, including 30 gynecology specialists and 10 gynecology residents, participated in the workshop. All participants of the workshop completed the questionnaires.

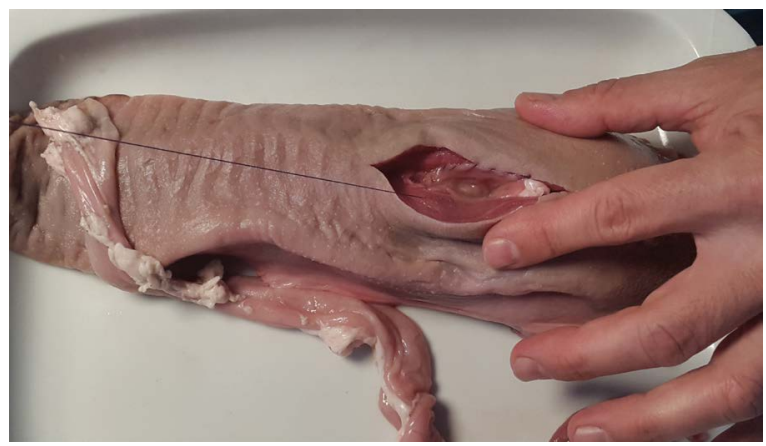

Figure 8. Suturing of the intestine at the site of the imitated vagina

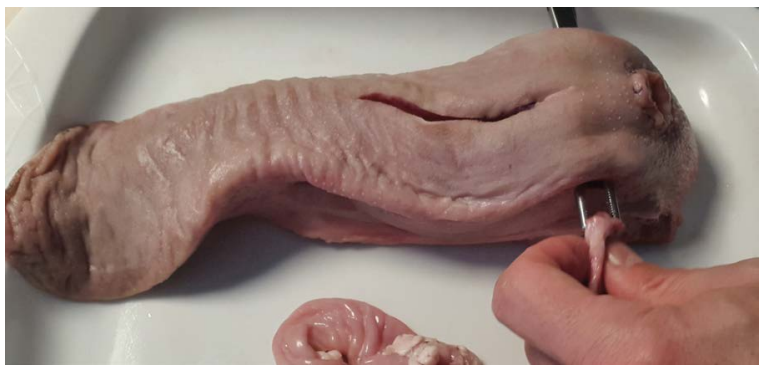

Figure 9. Passing of a muscle bundle imitating the sphincters

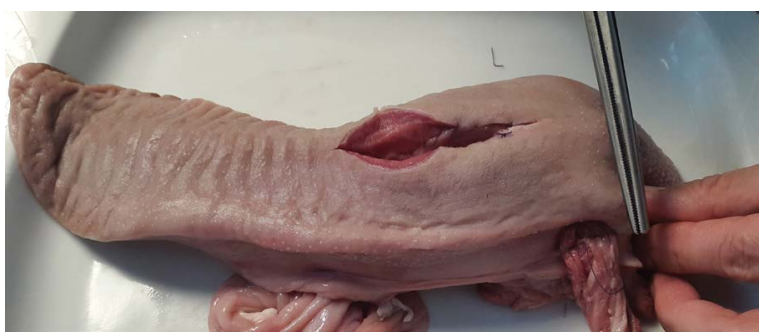

Figure 10. Suturing of ends of the created "sphincters" to the margins of the tongue 


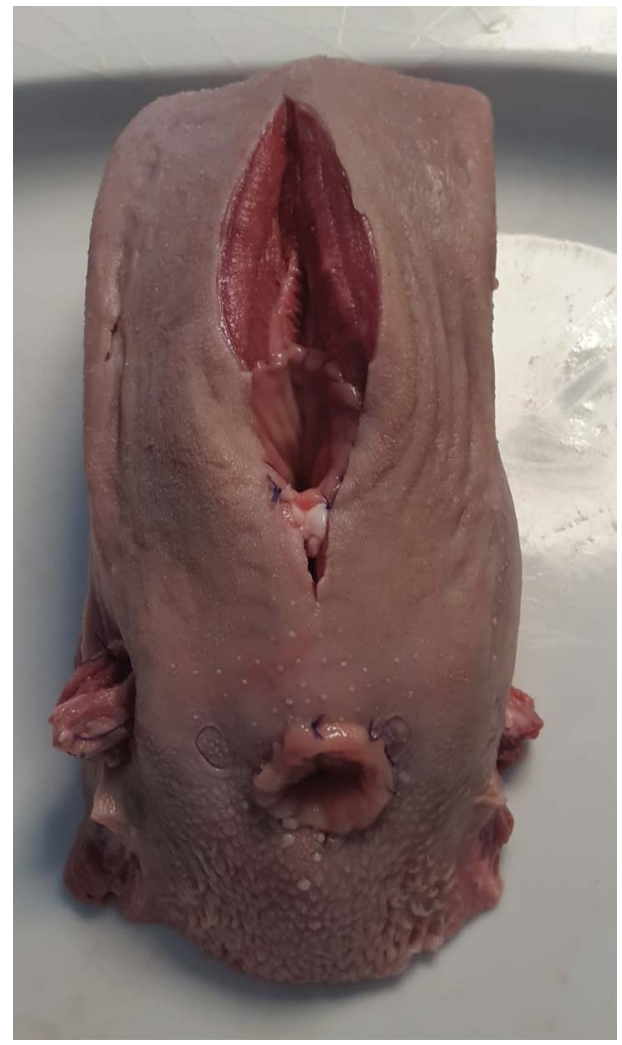

Figure 11. Final appearance of the created model

\section{RESULTS}

We found that 21 (52\%) workshop participants repair 3rd and/or 4th degree injuries 2 to 5 times a year, 24 (60\%) of the participants perform primary reconstruction single-handedly, and $16(40 \%)$ participants use the help of a surgeon to repair the injured perineal tissues. Interestingly, 38 (95\%) of the respondents had never trained perineal reconstruction on a model before. According to 34 (85\%) of the respondents, our model was very similar to natural tissues and 38 (95\%) of the respondent declared that the simulated model of the perineal tear satisfactorily mimicked the real life situation. The results of the questionnaire are presented in Table 1.

\section{DISCUSSION}

According to the literature, anal sphincter injury occurs in approximately 4 to $11 \%$ of natural childbirths $[3,4]$. The percentage of women with various degrees of incontinence resulting from perineal tear associated with natural childbirth is $15-61 \%$ (4-6) and it is directly related to the degree of the tear and quality of its repair. More than half of the respondents of our questionnaire reported that they encounter 3rd and/or 4th degree perineal tears two to five times per year, while the other respondents deal with it less than once a year. This injuries often require to be repaired by on duty physicians who are not always qualified to manage this type of perineal tears. Such a situation increases the

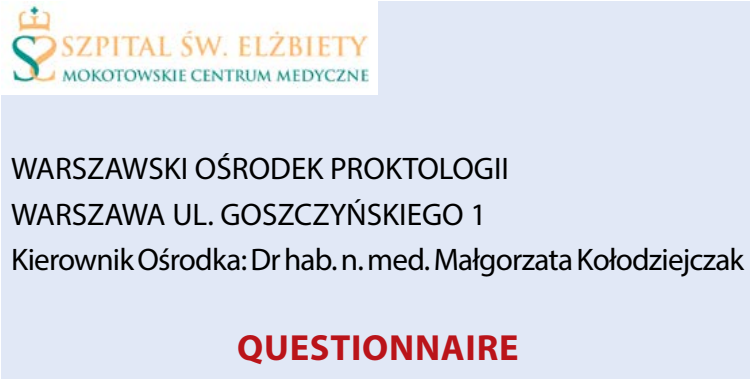

\section{Dear Doctor}

We provide you with a questionnaire regarding the assessment of the utility of the 3rd and 4th degree perineal tear model. The model is prepared from porcine tissues. We will be grateful for your answer to the questions below. Fill out the questionnaire and please return it after the lecture.

1. How often do you encounter $3^{\text {rd }}$ and $4^{\text {th }}$ degree perineal tear in your practice?
a) less than once a year
b) 2-5 times a year
c) more than 5 times a year

2. How do you manage $3 \mathrm{rd}$ and 4 th degree perineal tears? a) primary perineal and sphincter reconstruction on my own

b) perineal reconstruction without sphincter reconstruction on my own - delayed reconstruction after healing

c) primary perineal and sphincter reconstruction with the assistance of a surgeon

3. Have you ever trained using models of perineal tear?
a) yes, using an artificial and animal model
b) yes, only using an artificial model
c) yes, only using an animal model
d) no, never used any model

4. Do you think that the model is similar to natural tissues?
a) it is not similar
b) slightly similar
c) very similar

5. Does the simulated 4 th degree perineal injury satisfactorily mimic the real life situation?
a) yes
b) no Team of the Warsaw Proctology Centre

Figure 12. Sample questionnaire 


\begin{tabular}{|c|c|c|}
\hline Question & $\begin{array}{l}\text { Number of } \\
\text { responses }\end{array}$ & $\begin{array}{l}\text { Results } \\
{[\%]}\end{array}$ \\
\hline \multicolumn{3}{|c|}{$\begin{array}{l}\text { How often do you encounter } 3 \mathrm{rd} \text { and } 4 \text { th degree perineal tear in } \\
\text { your practice? }\end{array}$} \\
\hline less than once a year & 19 & $47.5 \%$ \\
\hline $2-5$ times per year & 21 & $52.5 \%$ \\
\hline more than 5 times a year & 0 & $0 \%$ \\
\hline \multicolumn{3}{|c|}{ How do you manage 3 rd and 3 th degree perineal tears? } \\
\hline $\begin{array}{l}\text { primary perineal and sphincter } \\
\text { reconstruction on my own }\end{array}$ & 24 & $60 \%$ \\
\hline $\begin{array}{l}\text { perineal reconstruction without sphincter } \\
\text { reconstruction on my own - delayed } \\
\text { reconstruction after healing }\end{array}$ & 0 & $0 \%$ \\
\hline $\begin{array}{l}\text { primary perineal and sphincter } \\
\text { reconstruction with the assistance of } \\
\text { a surgeon }\end{array}$ & 16 & $40 \%$ \\
\hline \multicolumn{3}{|c|}{ Have you ever trained using models of perineal tear? } \\
\hline yes, using an artificial and animal model & 0 & $0 \%$ \\
\hline yes, only using an artificial model & 1 & $2.50 \%$ \\
\hline yes, only using an animal model & 1 & $2.50 \%$ \\
\hline no, never used any model & 38 & $95 \%$ \\
\hline \multicolumn{3}{|c|}{ Do you think that the model is similar to natural tissues? } \\
\hline it is not similar & 0 & $0 \%$ \\
\hline slightly similar & 6 & $15 \%$ \\
\hline very similar & 34 & $85 \%$ \\
\hline \multicolumn{3}{|c|}{$\begin{array}{l}\text { Does the simulated 4th degree perineal injury satisfactorily } \\
\text { mimic the real life situation? }\end{array}$} \\
\hline yes & 38 & $95 \%$ \\
\hline no & 2 & $5 \%$ \\
\hline
\end{tabular}

risk of failure of the primary reconstruction. The second question of the questionnaire indicates that all respondents attempted primary reconstruction. This clearly shows that they are aware of the consequences of delayed perineal repair. Despite this, an average of $39 \%$ of women suffer from incontinence after childbirth [4]. Misdiagnosis of severity of the injury or incorrect primary repair are the cause of sphincter insufficiency in this group of women. Almost half (40\%) of the questioned gynecologists indicated that they asked a surgeon to help them in the reconstruction process. This could indicate lack of experience in reconstruction of 3rd and/or 4th degree tears. According to the respondents, the ability to practice on an animal model mimicking the natural tissues is not only the best, but also the only effective method to learn the surgical technique, which seems very desirable according to the answers presented in the ques- tionnaire. According to American researchers, the training of resident doctors on animal models improved their skills by approximately 15\%-30\% [7-9]. Observed improvement of skills was statistically significant in cited studies and the trainees preferred animal models to artificial ones (made of synthetic materials).

A vast majority of our respondents (more than 95\%) had never trained on any model mimicking the perineal tear. This emphasizes the need to promote the model as a tool to improve the qualifications of medical personnel. The respondents evaluated the model as highly similar to natural tissues (85\%) and real life situation (95\%). Such evaluation highlights the usefulness of the model as a training tool for physicians.

\section{CONCLUSIONS}

The model presented is cheap and easy to prepare. It satisfactorily mimics the tissues and tissue injuries caused by the tear, making it helpful in training physicians on the reconstruction of $3 \mathrm{rd}$ and 4 th degree perineal tear.

\section{Conflict of interest}

The Authors did not report any potential conflicts of interest. The study was founded by the authors only.

\section{REFERENCES}

1. Illston JD, Ballard AC, Ellington DR, et al. Modified Beef Tongue Model for Fourth-Degree Laceration Repair Simulation. Obstet Gynecol. 2017; 129(3): 491-496, doi: 10.1097/AOG.0000000000001908, indexed in Pubmed: 28178060.

2. Smith LA, Price N, Simonite $V$, et al. Incidence of and risk factors for perineal trauma: a prospective observational study. BMC Pregnancy Childbirth. 2013; 13: 59, doi: 10.1186/1471-2393-13-59, indexed in Pubmed: 23497085.

3. Dudding TC, Vaizey CJ, Kamm MA. Obstetric anal sphincter injury: incidence, risk factors, and management. Ann Surg. 2008; 247(2): 224-237, doi: 10.1097/SLA.0b013e318142cdf4, indexed in Pubmed: 18216527.

4. Harvey MA, Pierce M, Alter JEW, et al. Society of Obstetricians and Gynaecologists of Canada. Obstetrical Anal Sphincter Injuries (OASIS): Prevention, Recognition, and Repair. J Obstet Gynaecol Can. 2015; 37(12): 1131-1148, indexed in Pubmed: 26637088.

5. Kołodziejczak M. Poporodowa niewydolność mięśni zwieraczy. In: Leczenie chorób proktologicznych w okresie ciąży i porodu. 1st ed. Warsaw: Borgis. ; 2011: 135-138.

6. Reid AJ, Beggs AD, Sultan AH, et al. Outcome of repair of obstetric anal sphincter injuries after three years. Int J Gynaecol Obstet. 2014; 127(1): 47-50, doi: 10.1016/j.ijgo.2014.04.013, indexed in Pubmed: 25097141.

7. Patel M, LaSala C, Tulikangas $P$, et al. Use of a beef tongue model and instructional video for teaching residents fourth-degree laceration repair. Int Urogynecol J. 2010; 21(3): 353-358, doi: 10.1007/s00192-009-1042-3, indexed in Pubmed: 19924368.

8. Dancz CE, Sun V, Moon HB, et al. Comparison of 2 simulation models for teaching obstetric anal sphincter repair. Simul Healthc. 2014; 9(5): 325330, doi: 10.1097/SIH.0000000000000043, indexed in Pubmed: 25188488.

9. Siddighi S, Kleeman SD, Baggish MS, et al. Effects of an educational workshop on performance of fourth-degree perineal laceration repair. Obstet Gynecol. 2007; 109(2 Pt 1): 289-294, doi: 10.1097/01. AOG.0000251499.18394.9f, indexed in Pubmed: 17267826. 